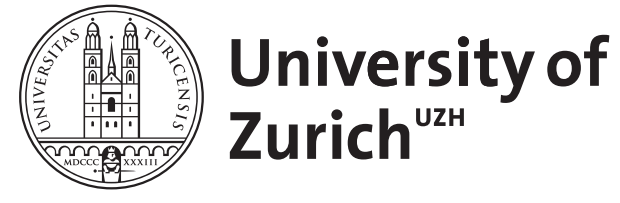

\title{
Short literature notices
}

\author{
Andorno, Roberto
}

DOI: https://doi.org/10.1007/s11019-013-9528-7

Posted at the Zurich Open Repository and Archive, University of Zurich ZORA URL: https://doi.org/10.5167/uzh-172007

Journal Article

Published Version

Originally published at:

Andorno, Roberto (2014). Short literature notices. Medicine, Health Care and Philosophy, 17(1):161-166. DOI: https://doi.org/10.1007/s11019-013-9528-7 


\title{
Short literature notices
}

\author{
Roberto Andorno
}

Published online: 28 November 2013

(C) Springer Science+Business Media Dordrecht 2013

Sadegh-Zadeh, K.: 2012, Handbook of Analytic Philosophy of Medicine (Philosophy and Medicine series, vol. 113). Berlin: Springer. 1133 pages. ISBN 978-94-007-2259-0. Price: $€ 222,45$.

Why are there so many "misdiagnoses, wrong treatments, and physician-caused misfortunes, pains and deaths" (p. 2)? Why are, according to one study, 30-38\% of all diagnoses incorrect (p. 4)? These intriguing questions triggered the research of Kazem Sadegh-Zadeh and led him into analytic philosophy of medicine, applying logical and conceptual analysis to this field. The result of his research is now collected into this enormous book that can be a useful source of inspiration for analysts of medical knowledge. It is, however, somewhat misleadingly labelled as a "handbook". The reader should not expect to find a balanced multi-perspective treatment of the field by a group of experts (like, e.g., the Elsevier-handbook edited by Fred Gifford), nor an introduction (like Medicine and Philosophy by Ingvar Johansson and Niels Lynøe), but rather the personal views of the author on an ongoing discussion. The volume is the fruit of nearly 50 years of thinking about the subject (p. 8, p. 814), and could thus be appropriately called the summa of a researcher's life.

The book starts with an analysis of medical language (pp. 11-106), medical practise (pp. 109-380) and medical knowledge (pp. 383-551). Then, it continues with medical deontics (pp. 555-583), medical logic (pp. 587-681) and medical metaphysics (pp. 685-786). To help with logic, the book comes with a 200-page appendix "Logical Fundamentals" (pp.

R. Andorno ( $\square)$

School of Law, University of Zurich, Rämistrasse 74/65,

8001 Zurich, Switzerland

e-mail: roberto.andorno@rwi.uzh.ch
821-1042!), rehearsing the standards of logic from set theory to fuzzy logic.

The author combines traditional topics like the verification problem and the structuralist account of theoretical entities with more recent topics like social epistemology and social ontology, and he even brings in the social constructivist theory from cultural studies. The author pictures medicine as a practical science on the verge to become an engineering science (p. 781). As a practical science, medicine consists of a bunch of practical rules, and not as much of assertions. According to the author, these rules are established as social institutions by way of social contract (p. 520). One of the problems of medicine is that central concepts like "health" and "disease" are undefined and vague, which leads Sadegh-Zadeh to borrow from prototype theory and fuzzy logic to suggest a formal framework for a definition of disease. Also, as a practical science medicine does not aim at truth. In fact, according to Sadegh-Zadeh, there is not much truth in medicine, "because it mainly consists of hypotheses and deontic rules", and if there is truth, it is "system relative" (p. 762).

Impressive as it is, I have some reservations about the Handbook. First, I think the author is overstating the constructivist perspective. It is true that today's medicine comes along with licensing processes, approved guidelines and legal regulations. But medicine has once started without this institutionalized superstructure, and at its borders as well as at its foundations it still has to do without. Second, Sadegh-Zadeh underestimates personal and non-propositional knowledge. His focus is exclusively on non-personal propositional knowledge. Nevertheless, he does not discuss the relevance of acquired personal abilities of medical practitioners and their implicit knowledge.

Third, there seems to be a tension between constructivist and verificationist strands within the book. As a social 
constructivist, Sadegh-Zadeh can admit that "no scientific knowledge is true" (p. 346). But this is not compatible with his argument that many sentences "can never constitute knowledge because, due to their [syntactic] structure alone, they are not verifiable and thus cannot turn out, or be considered, true" (p. 396). Moreover, these "truth-repellent syntaxes" (p. 758) are not well argued for. For the author, no unbounded universal statement is true (p. 486)-as this is itself an unbounded universal statement, it cannot be true. His claim is motivated by the assumption that universal conditional sentences are not verifiable in infinite domains, whereas existential statements are not falsifiable therein. This is, however, false: "All mammals are vertebrates" and "All multiples of 4 are even numbers" are both true, and the latter is even probable in the infinite domain of natural numbers, as well as "There is a highest prime number" can be shown to be false. Hence verifiability does not hinge on syntax but on semantic content; and even if a sentence turns out as non-verifiable, this would not imply that it cannot be true. Given Sadegh-Zadeh's institutional approach to medicine, it might have been better to refrain from using the language of "knowledge" and "truth" altogether and use the language of "acceptance" and "usefulness" instead.

These quibblings (and some others) aside, the book can be recommended to anybody who thinks about the rationality of medical treatments, philosophers and practitioners alike. The volume presents a cornucopia of useful material that could trigger further thinking on the topic. To its full extend, however, it will only be accessible to those that are willing (and able) to read logical notation.

\section{Ludger Jansen \\ Rostock, Germany}

\section{Reply to Dr. Jansen}

The acerbity in Dr. Jansen's review of the Handbook of Analytic Philosophy of Medicine is due to some misunderstandings which may be clarified in this brief note. My aim in writing the book was to lay the foundations for a new direction in the philosophy and methodology of medicine. This task included, among other things, the proposal to prefer in medical epistemology the communitarian approach to the traditional one. To this end, it was necessary to demonstrate that in medicine the traditional epistemology does not work because it is based on the classical concept of knowledge, introduced by Plato, according to which "knowledge is justified true belief" (Theaetetus 201c, d).

Both the two basic requirements of this conception, i.e., its justifiedness condition and its truth condition, are not satisfied in medicine. First, as yet there is no acceptable theory of justification available. And second, most of what is called knowledge in medicine, is not true. That does not mean that it is false, but only that it does not bear the truth value "true". This is so because it consists of deontic norms (diagnostic-therapeutic knowledge consists of ought-to-do rules of indication and contra-indication: pp. 308-316, 450-457, 578-581, 768-776) and theories and hypotheses. Ought-to-do rules are not statements to have any truth values. Theories do not have truth values either because they are conceptual structures and do not consist of statements to assert anything (pp. 403-441). As regards medical hypotheses, a hypothesis is defined to be a meaningful statement with indeterminate truth value ( $\mathrm{p}$. 396). These are the reasons why the concept of truth had to be considered in the inquiry and could not be bypassed, in contrast to what the reviewer suggests.

The chapter on medical epistemology which includes these analyses and is the target of the reviewer's attack, starts with the explicit announcement that "We shall be concerned with propositional medical knowledge only" (p. 384), i.e., with empirical-medical knowledge, but not with analytically true or inductively provable knowledge of formal sciences such as logic and mathematics. The reviewer's counter-examples, however, are just nonempirical statements from formal sciences of mathematics and logic.

By virtue of their logical syntax, several types of medical hypotheses are distinguished and it is shown why some of them are not verifiable, some are not falsifiable, and some others are neither verifiable nor falsifiable. Among the unverifiable ones are the unbounded universal hypotheses such as "all human beings are mortal". They are unverifiable because they talk about actually or potentially infinite domains. An empirical, medical hypothesis of this type whose truth value will never be known, is not true, i.e., it does not bear the truth value "true". As mentioned above, the counter-examples listed by the reviewer are not empirical hypotheses, but either analytically true or inductively provable sentences from formal sciences. In closing this clarifying rejoinder, it is worth noting that the only non-mathematical counterexample given by the reviewer ("All mammals are vertebrates") bore the truth value "true" for Aristotle. Today, it belongs to the class of unverifiable universal statements with indeterminate truth value. Thus, it is a hypothesis like any other one.

Many consequences have been drawn from these considerations in the chapter under discussion. One of them is that we need another concept of knowledge in medicine than the classical one, and another type of epistemology than the traditional one. A second consequence is that the Aristotelian two-valuedness (true, false) is outdated and 
must be abandoned in medicine because obviously medical knowledge is many-valued. Accordingly, the communitarian epistemology has been proposed in the book, on the one hand. And on the other hand, fuzzy epistemology, fuzzy ontology, and many other fuzzy-logical approaches have been incepted for use in medicine and philosophy of medicine.

\section{Kazem Sadegh-Zadeh \\ Tecklenburg, Germany}

Jasanoff, Sh. (ed.): 2011, Reframing Rights. Bioconstitutionalism in the Genetic Age. Cambridge, Mass.: MIT Press. 320 pages. ISBN 978-02-625-1627-3. Price: \$25.

This book contains a series of original papers on what Sheila Jasanoff calls "bioconstitutionalism", a term that emerged during conversations of the authors to "accommodate their empirical findings" (Kaushik Sunder Rajan, p. 193). What was needed then was a notion broad enough to encompass "biopolitical relationships with the institutions that regulate them" within the field described as "a constitutionalism with a small c" (Jasanoff, p. 10). The notion of bioconstitutionalism is less abstract and more promising than Foucault's biopower and biopolitics. Bioconstitutionalism is a bottom-up project which assumes the complexity of the examined situation, seeking to include the multiple layers of the reality it describes. It also shares a number of worries normally understood as bioethical, but it does it "by representing as fluid and negotiable many of the lines that ethicists have taken as given and immutable" (Jasanoff, p. 291) and by incorporating the concern for citizens' participation in the coproduction of law and science (this is the key expression of the book). In this regard, an idea that seems to be shared by a number of papers within the volume is the necessity of taking into account the preoccupations of those who are not experts in normative analysis, and "thereby contributing to the democratic governance of science and technology" (Jasanoff, ibid.).

The book's chapters cover not only various topics but also offer a valuable material which helps to understand major differences between countries (US, UK, Australia, Germany, Italy and India). Alex Wellerstein, in a chapter presenting the history of eugenics in the US in the twentieth century and the unusual frequency of this practice in California, shows that the motivations of the three influential figures of California's medical history of sterilisation were different and that it is difficult to extract from these attitudes a common strain of thought about eugenics. To put this simple label on a multi-factored phenomenon does not help to understand its determinations and cannot contribute to prevent it. In her own paper, Sheila Jasanoff compares American, British and German debates about embryo research and on the stages of development of the embryo. Giuseppe Testa presents three fascinating cases of "defining the entities derived by somatic-cell nuclear transfer" (i.e., cloned embryos or tissues), in the UK, Italy and the US. This comparison "reveals that this diverse ordering did not result from a confrontation between a predefined object and equally predefined legal and ethical principles that could either accept or reject it" (p. 102). Ingrid Metzler then offers an analysis of the relations between the Church and the State in Italy, and underlines the heterogeneous character of decisions concerning the entities crucial both from the biological and social point of view: contemporary biopolitics should thus not be reduced "to a single, coherent logic" (p. 118).

Jay D. Aronson analyses the question of a possible constitutional right to the post-conviction DNA testing and shows how problematic such an idea would be. David E. Winickoff's contribution recalls the main stages of construction of forensic DNA databases in the US to show how this new element in the penal law modified the way the law itself functions. Addressing the issue of xenotransplantation, i.e., the use of non-human biological material in humans, Mariachiara Tallacchini analyses the topic in Australia, Canada and the US, comparing those models with the European one, and showing how the pre-existing political structures influence the legal treatment of xenotransplantation. Kaushik Sunder Rajan writes about the emergence of genome science in the US and in India in the early 2000, and is interested in "capital and its relationship to global neoliberal formations" (p. 193) within the coproductions of law and life sciences studied being the subject of the book. In a text about human population genomics, Jeanny Reardon analyses the understanding of ethics within the Human Genome Diversity Project and the International Haplotype Map Project. If these projects have failed, she notes, it is because they have assumed a sharp distinction between science and ethics, where ethics was understood as an additional element that can be joined to the scientific enterprise and did not engage directly the responsibility of scientists.

In "Despotism and Democracy in the United Kingdom: Experiments in Reframing Citizenship", Robert Doubleday and Brian Wynne claim that the main issue at stake is the question of citizen's place in the debate over science, and express their worries that the direction taken in Britain is closer to a hegemony rather than to a genuine democracy, whereas the latter is the essential condition for the development of science. Finally, Jim Dratwa's chapter deals with the way the precautionary principle became a constitutive European policy understood by the author as a definitive tool to deal "with scientific uncertainties surrounding the regulation of biotechnology" (p. 263), and expressing a criticism of the governance of biotechnologies in Europe. 
The only regret that readers may feel while reading this rich interdisciplinary book is the absence of either legal theoretical or metaethical considerations. These fields are sometimes alluded to, but the professed desire to describe how things are without suggesting how they should be regulated can be frustrating for readers. Conceptual content of bioconstitutionalism needs to be elaborated if it is to be helpful for policymakers or for other scholars, and yet it is not clear whether such a theoretical development is compatible with the proposed project.

\section{Anna C. Zielinska \\ Heidelberg, Germany/Paris, France}

McDaniel, S. and Zimmer, Z. (eds.): 2013, Global Ageing in the Twenty-First Century. Farnham: Ashgate. 344 pages. ISBN: 9781409432708 . Price: $£ 58.50$

For many people, the increase in the proportion of elderly in a country's population, or in short, population ageing, is a phenomenon associated with industrialized countries, success in extending life expectancy, ageing baby boomers, and low birth rates (as in the case of Europe and Japan). However, experts in the field of ageing have been aware of the global nature of this trend for quite some time. For instance, as early as 2005, Alexander Kalache, Sandhi Maria Barretto and Ingrid Keller wrote a chapter on global ageing based on a substantial body of data and empirical research in the introductory portion of the Cambridge Handbook of Age and Ageing edited by Malcolm Johnson. The present volume contributes to this body of empirical sociological research, which is dedicated to exploring the different facets of global ageing. The editors, Susan McDaniel, Canada Research Chair in Global Population and Life Course at the University of Lethbridge, Canada, and Zachary Zimmer, Professor of Social and Behavioral Sciences at the University of California, San Francisco have compiled 17 chapters written by 28 experts from all over the world, the majority of which (17) are, however, based in North America. This may be due to the simple fact that the collection of papers dates back to a conference held in 2009 at the University of Utah.

In their short introduction, the editors stress that population aging now occurs in almost every country and every region of the world, creating different challenges from country to country. They briefly explain the universal reasons for population ageing, which can be best described as a decline in fertility and an increase in life expectancy. From this starting point, they sketch global differences. In the conclusion of their introduction, McDaniel and Zimmer highlight three challenges and opportunities of population ageing that they believe to be extraordinary: (1 Healthy ageing and health care, (2) Ageing workforce, retirement and the provision of pensions, and (3) Shifting intergenerational relations. These challenges or opportunities also determine the three main parts of the book, which certainly constitute a well-justified focus in the limited space the book allows for.

A second introductory chapter by François Héran, former director of the French National Institute for Demographic Research, describes four mechanisms of population ageing (ageing at the top or an increase in longevity, aging at the bottom or a fertility decline, the after-effect of a baby boom, and migration). He then continues to explain how these factors interact and draws different scenarios in various countries to explain the varying impacts each mechanism may have.

The following six chapters cast some light on various subjects related to the theme of health and health care. Moneer Alam and Arjouch et al. examine health and wellbeing in relation to gender in India and Algeria, Lebanon and Palestine. A chapter written by Eileen Crimmens and colleagues provides a very informative collection of data from comprehensive surveys in different countries on physiological change with age. A study from Taiwan confirms the data from other countries that people with religious beliefs, in this case mainly Buddhism, face less health problems with old age than non-believers. This is followed by an analysis of policies to meet the challenges of population ageing in Sub-Saharan Africa. Part I on the general theme of health and health care concludes with an interesting chapter that provides a general outlook on myths of health and ageing, namely that longer life expectancy is also linked to healthier living, that a longer life also means being in better health, and finally that future cohorts of people will be healthier. All of these myths are refuted with empirical data from the Netherlands, and the conclusion draws attention to different experiences of ageing depending on the social status of people.

Part II is dedicated to the challenges of an ageing workforce. It begins with a chapter by Codrina Rada providing evidence for the assumption that the impact of a labor constraint will be smaller than many economists fear. Kathrin Komp then examines new patterns of the participation of older people in the European workforce. She states that old age is redefined by an increase in workforce participation before and after retirement. The next chapter provides a more skeptical look at the particular case of ageing IT workers, which also concludes Part II. The next theme of intergenerational relationships is introduced by a chapter on global changes in family structures and marital status in old age, with an additional focus on gender. More specifically, this chapter not only analyses how care needs are met in relation to gender and marital status and but also shows how difficult the experience of older widows is in 
many states with poor welfare provision. The experience of giving and receiving care is also addressed by the two subsequent chapters. The first deals with this topic by exploring different attitudes towards old age and social capital, while the second examines its economic impact on the caregivers and consequences for their social participation. The fourth chapter in this section presents the finding that elderly adults in Eastern Europe experience more loneliness than their Western European counterparts, which is due to multiple factors and requires a particular political response. Complementing this picture of loneliness resulting from a reduced family size, the following chapter highlights the importance of family support for the elderly as well as the need to support families in this role if population ageing occurs. Finally, the editors briefly summarize each chapter and attempt to draw conclusions for future scientific and policy issues arising from the research results of each article.

For ethicists, this book may offer two general findings: the first is the richness, diversity and ethical relevance of the empirical, mostly qualitative sociological research on ageing presented here. This ranges from questions of priorities in health care and social justice to theories of the good life. The second is the complete absence of an elaborate ethical expertise despite the omnipresence of ethically relevant propositions and implicit normative assumptions. Only Héran briefly mentions moral philosophy in his introductory chapter but refrains from elaborating further on the implications thereof. However, it may very well be that several questions can only be answered in collaboration with ethics experts such as those concerning the meaning of a "favorable age structure" of a society or why global inequality is wrong and which duties may result from it - a question that is implicitly raised by the editors in the concluding chapter. All in all, it is a very interesting volume with a comprehensive body of scientific research that grants ethicists the opportunity to learn from it and make their own voice heard in debates on global ageing.

\section{Hans-Jörg Ehni}

Tübingen, Germany

Emmerich, N.: 2013, Medical ethics education: An interdisciplinary and social theoretical perspective. Heidelberg: Springer. ISBN 978-3-319-00484-6. 111 pages. Price: $€$ 41.64

Medical ethics is nowadays recognized as a field of proper academic investigation and empirical research. As an expression of the ongoing diversification, philosophical, conceptual and practical issues are discussed by scholars from different disciplines. In order to fully understand the (sometimes quite puzzling) variety of results, the underlying conceptual frameworks that drive the direction of inquiry have to be carefully analyzed. Such frameworks are far from being homogeneous: they can focus on knowledge acquisition, moral development, behavior modification or professional socialization. Depending on these frameworks and on the underlying assumptions, different conclusions can be drawn about the very nature of medical ethics and the impact it should have on medical practice. As the brilliant study of Nathan Emmerich shows, this question is far from being idle, especially when it comes to discuss its implications for undergraduate medical ethics education and the processes that are at the root of ethics teaching and learning. Importantly, the latter do not only take place in the classroom, but also on the ward and at the bedside, where students are progressively socialized in the moral standards of the profession.

As the author highlights in the introductory chapter, it has been the sociological lens on medical education to visualize the dynamics between the formal and the informal (or hidden) curriculum students are exposed to during their studies and clerkships. With this lens, the book offers an overview of the inner-sociological discourse on medical education, with a proposal to move forward from the traditional concept of professional socialization-as the ultimate scope of medical ethics education-to the concept of enculturation which endorses the practical as well as educational purpose of justifying the practice of medicine. For Emmerich, this reconceptualization has the advantage of facilitating the transfer of knowledge into practice and transform knowledge departing from practice. Enculturation comprises "...the use of a particular language, a particular way (or mode) of (reflective and metacognitive) thinking that enables the medical professional...to engage in a practice that explicitly addresses the ethical dimensions.... as requirement of modern medical practice (p. 19)." Against this background, the dichotomization of theory and practice-described as one major problem of current approaches to the teaching of medical ethics — can be overcome by focusing on the students' progressive involvement in the different communities of practice they are socialized in-be it the classroom, the ward or the peer group. The second chapter depicts salient features of Pierre Bourdieu's social theory and discusses its relevance for medical ethics education. In contrast to the "classic" term of socialization and Bourdieu's notion of inculcation, Emmerich presents enculturation as an active and creative process triggered by language (p. 17).

From a normative point of view, this epistemic effort results in a "reappropriation" of medical ethics by its agents in form of thinking dispositions that have to be cultivated within formal and informal learning contexts of medical ethics. It's the modality of doing medical ethics, the "how" it is done, that stands at the center of the attention, and not the 
"what" or the set of answers it gives: "The normative aspect of bioethics does not lie in the 'solutions' to ethical questions it may offer but in regards the way ethics ought to be done ( $\mathrm{p}$. 37)." An overview over the development of medical ethics and medical ethics teaching within the UK is offered in chapters 3 and 4. Although informative, a stronger link between this historical-systematical account and the sociological account previously depicted would have been helpful. The last two chapters offer a well elaborated, systematic account of medical ethics education from the perspective of enculturation with an excellent, concise description of its intellectual sources in social theory and psychology.

The author's conclusion that medical ethics "...has become part of medical practice and education" (p. 52) is critical and unveals the normative implications of enculturation by factually levelling the tension between medical ethics and medical morality. It would have deserved more attention for at least two reasons. First, it recalls the distinction between facts and values within medicine as a practical science, the ambiguity of innovations and their possible applications (e.g., neuroimaging and penal law, health technology assessment and sustainability). Second, by levelling the difference between medical morality and medical ethics, the boundaries between the enculturation view and the "meliorist" view of medical ethics (justifiably rejected by the author) become blurred. At the end, it is hard to conceive how this "culturalisation" of medicine alone can transform medical practice into good practice, especially in the face of normative tensions concerning the ultimate goals of medicine or cases of overt malpractice. Enculturation is undoubtedly an intriguing and potent metaphor and the author succeeds in presenting it as a necessary condition of education for professionalism. Nevertheless, it has to be proved whether it is a sufficient one to face all the ethical dimensions of contemporary medicine and medical education.

\section{Settimio Monteverde}

Zurich, Switzerland

Arbuckle, G.: 2013, Humanizing healthcare reforms. London: Jessica Kingsley Publishers. 272 pages. ISBN: Price: $\$ 39.95$.

This volume stems from a lecture series that Dr. Gerard Arbuckle gave at Oxford University in 2011, which focused on the theme 'Healthcare in Chaos: Models in conflict'. The author is a trained anthropologist and a cultural and organisational consultant to public and private healthcare systems in the United States, Canada, and Australia.

Dr. Arbuckle notes that the growing prevalence of chronic diseases and demographic changes in the last 20 years has had a serious impact on the functioning of healthcare systems. The current persistent imposition of financially-based performance indicators to healthcare systems worldwide pose serious challenges from an ethical point of view. The author argues that a return to a values-based approach to healthcare will create positive transformation.

Writing from the perspective of social anthropology, Dr. Arbuckle describes the crisis that affects different levels of the medical sector and offers practical advice about the modifications that should be made to reach a stable health system. Healthcare reforms must modify some of the most common values of the market place such as autonomy, individuality, self-determination and diversity. Although the patient's rights must be preserved, this should not be at the expense of social values. The author stresses that this goal is achieved only when a new system is based in fundamental cultural values such as compassion, solidarity and social justice. Healthcare organizations must be able to identify them; indeed, clinicians, managers and leaders face this challenge within healthcare organizations. The entire team must be engaged with the common accepted mission and values and remember that communication is a key element of collaboration. In fact, managers and clinicians should train themselves to develop communication skills and to be able to cross cultural diversity barriers because healthcare reforms policies require skilled leaders who are able to implement the appropriate policy decisions.

The first four chapters of the volume emphasize the crucial role of culture in healthcare decisions, while the remaining three chapters examine the steps to follow to improve existing healthcare systems. After defining anthropologically the concept of culture and its constituent elements (chapter 1), the author identifies and describes five models of healthcare: traditional, foundational, biomedical, social and economic rationalist (chapter 2). The third chapter explains the main reasons for the tensions between clinicians and managers regarding healthcare reforms, and the risks that this conflict may pose to patients. Chapter four ("Bullying in Healthcare Institutions: An anthropological Perspective") encourages readers to identify the problems which causes bullyism within the healthcare system, while the following chapter focuses on the issues of leadership and cultural change. Chapter 6 explains the reasons for the most common mistakes in mergers in healthcare. The last chapter summarizes the advantages of faith-based healthcare institutions and the risks they may cause. Each chapter includes an index of the themes, a case study, a summary and a strategic implication. This very accessible book will be a helpful guide to anyone interested in a better approach to healthcare reform, from clinicians and nurses, to managers and policymakers.

Cristiana Baffone

Bologna, Italy 